\title{
La Geografía y la Gestión Cultural: hacia el ordenamiento de la Ciudad-Patrimonio ${ }^{1}$
}

\author{
Cultural Management and Geography: toward the order \\ of the City-Heritage
}

\author{
Doris Milena Correa Barragán \\ Universidad Cooperativa de Colombia \\ Facultad de Psicologta
}

\begin{abstract}
Resumen
El presente artículo busca reconocer los aportes de la geografía y la gestión cultural a la exaltación del valor del patrimonio, dentro de los procesos de ordenamiento territorial de la ciudad. La reflexión se traza desde una mirada a la ciudad y al centro histórico como espacios patrimoniales, para luego dirigirse a explorar algunos de los conceptos que aportan corrientes geográficas como la geografía histórica, de la percepción y urbana, tomando la ciudad -material e imaginada- como productos de la territorialidad y la memoria colectiva. Finalmente, se presenta una serie de elementos a considerar en el disefío de alternativas de intervención a espacios patrimoniales, mediante estrategias y sus respectivas acciones, que incluyen, en esencia, tanto los aportes de la geografía, como las herramientas metodológicas de otras disciplinas como la arquitectura a la gestión del patrimonio.
\end{abstract}

Palabras clave: Patrimonio, Ciudad, Centro histórico, Geografía histórica, Geografía de la percepción y Geografía urbana, Gestión cultural.

${ }^{1}$ Articulo que se desprende del trabajo de grado titulado Gestión Cultural y Uso Social del Centro Histórico. Barrios La Merced y San Anton io de la ciudad de Cali. Tesis meritoria Universidad del Valle. Facultad de Human idades. 2008.

${ }^{2}$ Geógrafa y Licenciada en Ciencias Sociales egresada de la Universidad del Valle. 


\begin{abstract}
This article seeks to recognize the contribution of the cultural management and geography in the exaltation of the heritage value, within the land use processes of the city. The thinking is drawn from a glance at the city and the historical center as patrimonial spaces, and then turns to explore some of the concepts that contribute geography approaches such as historical geography, of perception and urbanity, taking the city material and imaginary as products of territoriality and collective memory. Finally, a series of elements to take in consideration are given, related to the design of altematives of intervention of patrimonial spaces, through strategies and its respective actions which include both, geography contributions, as the methodological tools of some other disciplines like architecture to patrimonial management.
\end{abstract}

Keywords: Heritage, City, Historic center, Historical geography, Urban geography and geography Perception, Cultural management.

\title{
1. Introducción
}

El patrimonio entendido como lo que se quiere legar, aparece como lo expresa Josep Ballart "cuando en el paso de las generaciones, un individuo o grupo, identifica como propios un objeto o conjunto de objetos"3. Por ello, la declaración de un bien o un lugar como patrim onial al interior de la ciudad, debe ser producto, en esencia, de reconocer una correspondencia identitaria y de apropiación colectiva.

En este contexto es pertinente exponer, para el caso de Colombia, 10 que es incluido en el concepto de patrimonio, ese conjunto de bienes que se desean conservar, por ello el Ministerio de Cultura, en la Ley 397 de 1997 (Artículo 4\%. Definición de patrimonio cultural de la Nación.) establece:

${ }^{9}$ BALLART, Joseph. El patrimonio histórico y arqueológico: valor y uso. Barcelona: Ariel, 1997.p-36 
El patrimonio cultural de la Nación está constituido por todos los bienes y valores culturales que son expresión de la nacionalidad colombiana, tales como la tradición, las costumbres y los hábitos, así como el conjunto de bienes inmateriales y materiales, muebles e inmuebles, que poseen un especial interés histórico, artístico, estético, plástico, arquitectónico, urbano, arqueológico, ambiental, ecológico, lingüístico, sonoro, musical, audiovisual, fílmico, científico, testimonial, documental, literario, bibliográfico, muscológico, antropológico y las manifestaciones, los productos y las representaciones de la cultura popular ${ }^{4}$.

Teniendo en cuenta la gran cantidad de creaciones que pueden entrar en este listado de categorías consideradas dentro de la concepción de patrimonio, es un compromiso indiscutible de las sociedades, encaminar sus prácticas hacia la conservación de estas producciones. Esta base de respeto por los bienes patrimoniales garantiza una planificación territorial orientada al desarrollo de elementos y significados culturales presentes y fiuturos que no se fundamentarán en el detrimento u olvido de los que le anteceden; así, se valora el pasado, se comprende la realidad actual y se establecen responsabilidades a futuro con el patrim onio que se dejará de herencia.

Siguiendo a Miguel Vinuesa, "la cindad, además de ser un paisaje cultural en expansión, es una realidad dinámica donde los problemas de reorganización interna del espacio urbano, llámense de reforma interior, renovación, remodelación o rehabilitación, han estado siempre presentes", lo que demanda modelos de análisis, desde diferentes perspectivas geográficas que propicien la aplicación de conocimientos e instrumentos que se materialicen en programas de actuación acordes con las realidades socioeconómicas, históticas y culturales del territorio cambiantes en el tiempo.

${ }^{4}$ Ministerio de Cultura. Ley 397, 1997 [online]. Versión HTML. Santafe de Bogotá. 1997. [Citado 26 de octubre, 2006]. Disponible en wwwmincultura.gov co/legislación

${ }^{5}$ Universidad Complutense. Centro histórico, intervención urbanistica y análisis urbano. VTNUESA, Mignel. Revista Analen de Geografia. No 11. Añ 1992. [OnLine]. [Version PDF]. [Citado 24 noviembre, 2008]. Disponible en: http//dialnet.unirioja.es/servlet/revista 


\section{Ciudad y centro histórico: productos y productores de patrimonio}

Para iniciar, se invita al reconocimiento de la Ciudad y el Centro Histórico como productos sociales y productores de patrimonio, pues se constituyen en escenarios de expresiones culturales, pero también de inquietudes y contradicciones, tefiidos de otígenes y transformaciones tanto de los espacios, como de los símbolos y de las formas de leerlos.

La Ciudad y el Centro Histórico, no sólo son imágenes de calles pavimentadas, empedradas, o de grandes edificios y plazas de antafio, en ellos se construye la cultura urbana mediante la acción ciudadana, que configuran el mosaico urbano, que de acuerdo a Armando Silva es "la mezcla de colores, ruidos, formas, y signos; como una especie de permanentes collages cubistas o surrealistas, en los que subyacen múltiples iniciativas, con la que cada ciudadano recorre la cindad, construye sus relatos, los representa, o los recuerda"s.

Es mediante los usos dados por las necesidades particulares y colectivas, como se da forma a los espacios de la ciudad, vista de un modo funcional, por R. Abler, J. S. Adams y P. Gould como:
(...) Una organización espacial de personas y actividades espe- cializadas diseñadas para maximizar los intercambios; a nivel local, la ciudad es el mejor medio de interrelacionar actividades sociales y económicas para máximo beneficio de todas ellas; a nivel regional, aparecen sistemas de ciudades para organizar intercambios entre lugares distantes y para facilitar a las áreas circundantes de carácter no urbano los bienes y servicios que necesitan ${ }^{7}$.

'Silva, Armando. Imaginarios urbanos. Bogotá y Sao Paulo: culturay comunicación urbana en América Latina. Bogotá: Tercer Mundo, 1992. 293p.

7 Abler, Ronald; Adams, John S., y Gould, Peter: Spatial organization. The Geographer's view of the World, Londres y Englewoods Cliffs, Prentice Hall International Inc., 1972, p354. Citado en: Defnición de Io urbano. CAPEL, Horacio. Revista Geocritica, publicaciones sobre geografia y ciencias sociales. $\mathrm{N}^{\mathrm{N}} 138$. [Onilne]. [Versión PDF]. [Citado 28 julio, 2007]. Disponible en: www.ub.geocrit/sv-33.htm 
Al dirigimos a una escala más local, dentro de la ciudad se encuentran los barrios, definidos por Pedro Buraglia, como "el entomo inmediato al hogar, el lugar de proximidad y reconocimiento, referente espaciotemporal de suefios, eventos y deseos; es recreado como una unidad de vecindad, coherente, aprehensible y armónica". Puede considerarse entonces, como un espacio de vida cotidiana y de residencia, donde se conjugan y materializan los ideales de la sociedad que lo habita y a su vez lo transforma, de modo que la imagen que se construye del barrio, constituye un elemento de referencia e identidad, que determina las particularidades de los diferentes espacios de la ciudad.

Por su parte, el Coloquio de Quito en 1977, definió los Centros Históricos como "aquellos asentamientos humanos vivos, fiertemente condicionados por la estructura física proveniente del pasado, reconocibles como representativos de la evolución de un pueblo". ${ }^{9} \mathrm{~A} 1$ interpretar esta definición, vale la pena sefialar que el Centro Histórico es ese espacio que va más allá de los elementos físicos, (casentamiento humano vivo") pues ese patrimonio arquitectónico, sólo tiene sentido al unirse a los usos y los significados dados por la población que los habita y los siente suyos; por tanto es el lugar para la identidad de las generaciones de ciudadanos que depositan en él, las expresiones de las distintas dimensiones sociales como la política, la economía, el poder y la sensibilidad de los valores patrimoniales.

De modo que, al reconocer que la definición de parámetros para delimitar el espacio de un Centro Histónico está influenciada por la escala temporal, se debe tomar en cuenta, que en éste se establece la estrecha relación antigüedad-modernidad, la cual no debe ser excluyente, pues lo modemo es producto de la evolución de lo antiguo y al identificar qué es lo modemo, se hace referencia a la existencia de algo que lo precedió, lo antiguo.

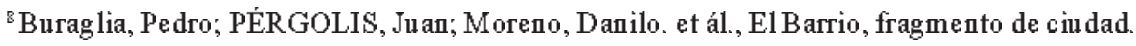
Bogotá: Barrio Taller. 1998.70p.

${ }^{9}$ Documento final del Coloquio de Quito, Proyecto Regional de Patrimonio Cultural, PNUD/ UNESCO, Qu ito, 1977, citado por HARDOY, Jorge Enrique y Gutman, Margarita. Impacto de la urbanización de los centros históricos de Iberoamérica. Tendencias y perspectivas. Madrid: MAPFRE, 1992 . p-27.
} 
Adicionalmente, la Ciudad y el Centro histórico, deben ser pensados en prospectiva pues, el elemento temporal, está en constante movimiento y a su vez determinará las próximas nociones del mismo. Igualmente, al delimitar el espacio del Centro Histórico, se tendrá como criterio básico, que éste es el lugar donde se concentra la mayor cantidad de pasado, representado por elementos que son reconocidos en la colectividad como históricos o de identidad, conjugados por supuesto con los usos actuales, por lo que no puede comprenderse aislado de la Ciudad, pues de esta depende sll existencia y características.

En este sentido el Centro Histórico puede presentar tanto el legado de los acontecimientos institucionales pasados, por medio de edificios, plazas y monumentos, com o puede convertirse en el espacio de expresión de la cultura actual, que junto al uso residencial, donde se da valor al vecino y a las prácticas comunitarias, puede tomar un sentido de espacio vivo y dinámico.

Una de las apreciaciones que se ha establecido para delimitar el Centro Histórico, es que sea un conjunto de edificios construidos en un período relevante de la historia, procurando que en él, se incluya parte del sitio fundacional de la Ciudad donde alguna vez se desarrollaron las actividades administrativas de ésta. Además debe indagarse, de modo estricto, las características funcionales de los mismos. En cuanto a esto, Fernando Carrión ${ }^{10}$ resume en tres momentos, la centralidad de las ciudades latinoamericanas:

1. La centralidad de la ciudad es única e indiscutida, se construye desde lo público, lo estatal y en espacios abiertos, y tiene como símbolo fundamental a la plaza principal o mayor.

2. Las centralidades se construyen desde lo privado, lo empresarial y en espacios cerrados. La plaza pública centralmente constituida cede ante el centro comercial privado, producido por el mercado.

3. La centralidad dada por el reemplazo del espacio de los lugares por el de los flujos, senderos y tránsitos, con lo cual prevalece el movimiento de las personas, la información, y los recursos.

10 Carrión, Fernando. Centro Histórico: relación social, globalización y mitos. En: Desarrollo cultural y gestión en centros históricos. Quito: FLACSO, 2000. 256p. 
Esta descripción denota, por un lado, que la concepción de centralidad está determinada por las expresiones de los intereses económicos, políticos y sociales a través del tiempo, y por otro, por el reconocimiento de la sociedad, como ese sitio de reunión, administración o en el último caso, el espacio para los tránsitos y los negocios; por lo que debe reevaluarse constantemente la participación de los miembros de un colectivo en la construcción de imaginarios que apunten a un Centro Histórico, con gran valor de imagen para que sea atractivo al turista, al migrante; pero también a que se avive el valor de uso para la Ciudad, que en esencia recoge los valores histórico-culturales de la población local.

Debe ser entonces, la Ciudad tangible y la imaginada, el objeto de estudio de una geografia, que brinde elementos de comunicación e identidad, para idear altemativas de intervención de los espacios materiales, a modo de guía que de a conocer los imaginarios colectivos, donde se ordene el territorio de "todos".

\section{Perspectivas geográficas para vivir los lugares-patrimonio}

Al pensar en una geografia comprometida con el reconocimiento y divulgación del patrimonio, se debe insistir en que se tome en cuenta enfoques con los que se contribuya a estudiar la identidad culturalterritorial, expresada en la memoria colectiva y los valores que evocan los lugares, para la comprensión de la morfología de la ciudad material. Esto implica entonces, abordar los intereses de comientes geográficas como la geografia histórica, de la percepción y urbana .

Para Ballart, la pérdida de memoria colectiva y referentes patrimoniales inmersos en las tradiciones de una sociedad, es tan alarmante como la afectación al entomo natural, al expresar que:

La modificación del entorno físico, con los cambios provocados en el paisaje y la práctica desaparición en todo el planeta del entorno natural primigenio, el crecimiento demográfico y los grandes movimientos de población, el incremento del medio edificado, el aumento de la contaminación atmosférica y de las aguas, alertan a la población del 
mismo modo que le sentimiento de pérdida de la relación con el pasado y la tradición ${ }^{11}$.

Dentro de la comprensión y valoración del patrimonio, es primordial superar el desconocimiento de las historias cotidianas surgidas en los espacios de la ciudad, y en las que se evoca la significación del pasado que es identificado como común, junto a la subjetividad de la imagen vivida en el devenir y que tiene un sin número de matices, como lo expresa Ricardo Vergara al sefialar que la imagen de la ciudad y de los centros históricos se constituye como resultado de "las percepciones de hombres y mujeres, que interpretan a su manera, un idioma, un acento, unos signos, símbolos, historias, mitos, leyendas, tradiciones, costumbres, funciones, fiestas y manifestaciones culturales"12. Es allí donde se encuentra la imagen de la ciudad que no sólo se ve sino que se imagina como ideal.

En la geográfica histórica, subyace el interés por desentrafiar cómo fue la distribución espacial de las sociedades que antecedieron a las actuales, dando cuenta de su morfología y usos de suelo; conlleva entonces, como lo afima Saller, a comprender que el "geógrafo no puede estudiar casas y pueblos, campos y fábricas, en lo que respecta a su ubicación y su razón de ser, sin preguntarse por sus orígenes. No puede tratar la localización de actividades sin conocer el funcionamiento de la cultura, los procesos de vida en comunidad del grupo, y solo puede hacer esto mediante la reconstrucción histórica"13.

Ahora bien, este mismo autor, establece que el trabajo de campo en geografia histórica, debe incluir comparaciones de lugares y actividades desaparecidas con las actuales, los trazados de las antiguas vías de

${ }^{11}$ Ballart, Op.cit. p-43

${ }^{12}$ Universidad del Norte. Grupo de Investigación en Arqueologia, Historia y Estudios Urbanos del Caribe Colombiano del Departamento de Historia y Ciencias Sociales. Transformaciones de la imagen de una ciudad: repercusiones de la renovación urbana. Vergara, Ricardo. Memorias: Revista digital de Historia y Arqueologia desde el Caribe. [Online]. [Versión PDF]. Barranquilla. Septiembre 15 de 2006. [Citado 7 de geptiembre, 2007]. Disponible en wwwuninorte.edu.co/ publicaciones/memorias

${ }^{19}$ Saluer, Carl. Introducción a la geografia histórica. Revista Polis. [Online]. [Versión html]. [Citado 18 de noviembre, 2008]. Disponible en: www.revistapolis.cl/8/geo.htm 
comunicación, las características del entomo natural, y demás aspectos que contribuyen a idear una imagen del paisaje y sus transformaciones. ${ }^{14}$

En este sentido, con los actuales procesos de transformación del uso de los espacios dentro de la cindad, se presenta la desaparición de referentes urbanos y con ella la poca o nula valoración de los significados acerca de la vida cotidiana de las generaciones pasadas, que conforman una parte del patrimonio legado. En este contexto, el compromiso del quehacer geográfico, debe enfocarse hacia reconceptualizar los lugares por su valor cultural y comunicacional, teniendo en cuenta la percepción y el imaginario individual y/o colectivo, regresando a la visión de los lugares para el encluentro, en donde se promueve el reconocimiento de las identidades.

Es así como en los significados que suscitan los espacios, se exalta la memoria colectiva de los ciudadanos, que encuentran en el patrimonio natural, edificado, los monumentos, las actividades cotidianas y las prácticas culturales, un valor pedagógico con el que se configura y promueve un mapa colectivo donde se consolida su territorialidad. Es con el desarrollo de una geografía histórica como se contribuye a reconocer, de acuerdo con Ballart, que "el pasado es el ingrediente necesario al sentido de identidad, o lo que es lo mismo, la sensación de pertenencia, gracias a que pone en evidencia el hilo ininterrumpido del paso del tiempo y la noción misma continuidad. Este hilo llena de vida, de vivencias porque une nuestros orígenes con nuestra identidad fluyente ${ }^{15}$.

Ahora bien, una mirada desde la geografia de la percepción, contribuye a la comprensión de la construcción de identidad territorial, bajo el concepto de lugar, el cual remite a la permanente comunicación entre los imaginarios de la sociedad y el espacio que ocupan. La valoración del espacio habitado bajo el concepto de lugar, incluye al pasado y al presente, es una construcción que ha sido "elaborada" por los seres humanos. Un parque, una esquina o un edificio existen como producto de una idea que se ha concretado en el imaginario de un colectivo y es expuesta en una realidad tangible, constituyendo un lugar.

\footnotetext{
${ }^{14}$ Ibid.

${ }^{15}$ Ballart. Op.Cit. 1997. p43
} 
La geografia de la percepción identifica las dinámicas y significados del comportamiento social, que en general, es territorial, incluye valoraciones como lo propio y lo ajeno, la inclusión y la exclusión, ya que al considerar propio un sistema espacial se acoge como lo ordenado, lo conocido y dentro del cual los individuos participan de su construcción. De ahí que la formación de identidades supone la apropiación territorial, basada en valoraciones socio-espaciales. Como lo expresa Mercedes Millán: "la geografia de la percepción se centra en los valores findamentales de la totalidad de las experiencias, en el concepto de lugar como centro de significado, como identificación personal y foco de vinculación emocional para el hombre y por extensión, en los conceptos de localización y deslocalización que ejercen, respectivamente, la función del arraigo y del desarraigo humano"st'.

Según Anne Buttimer parece que el sentido de identidad personal y cultural de la gente está íntimamente unido a la valoración del lugar. La pérdida de la tierra natal o "la pérdida del lugar de uno" pueden con frecuencia desencadenar una crisis de identidad ${ }^{17}$. Así la importancia del reconocimiento de los significados inmersos en el concepto de lugar, radica en que éste contribuye a la consolidación de identidades territoriales y culturales.

Dentro de los instrumentos de análisis de la geografia, con los que es posible la identificación de referentes espaciales de gran valor cultural, se encuentra la cartografia social, que junto a los mapas mentales abarcan aquellos procesos que hacen posible que la gente adquiera, codifique, recuerde y use la información acerca de la naturaleza de su ambiente espacial. Permiten la representación espacial y la percepción ambiental, además de proveer una clave para entender algunas de las estructuras y procesos del comportamiento humano en el espacio.

En este sentido, de acluerdo con Lynch: "la clave para comprender el sentido de lugar, es el análisis de las imágenes mentales que la gente

\footnotetext{
${ }^{16}$ Universidad de Murcia. Millán, Mercedes. La geografia de la percepción : una metodología de análisis para el desarrollo rural. [Online]. [Versión PDF]. Revista Papeles de Geografia. Murcia, España.14 de febrero, 2005. [Citado 23 de septiembre, 2007]. Disponible en: www. um.es/dp-geografia/

${ }^{17} \mathrm{Uttimer,} \mathrm{A.} \mathrm{«Hogar,} \mathrm{campo} \mathrm{de} \mathrm{movimiento} \mathrm{y} \mathrm{sentido} \mathrm{del} \mathrm{lugar».} \mathrm{1985.} \mathrm{En:} \mathrm{García,} \mathrm{Ramón.}$ Teoria y método en la geografia humana anglosajona. Ariel, Barcelona, 1978.
} 
tiene de su espacio y de su tiempo vitales. A partir de esta comprensión, las politicas de ordenamiento territorial, pueden estar dirigidas al fortalecimiento de esas imágenes, ya sea mediante cambios físicos, regulación de las actividades o reformas institucionales o educación" ${ }^{\text {"18. }}$. Con esto, es claro que se deban apreciar las expresiones espaciales colectivas, para que se logren acciones acertadas en la planificación y gestión de los recursos de los lugares, procurando mantener los valores de identidad que los individuos le imprimen a éstos a lo largo del tiempo.

Los mapas mentales se constituyen en una herramienta gráfica para el estudio de la relación entre los individıos y su territorialidad, que al ser interpretados pueden brindar la identificación de elementos espaciales como las sendas, constituidas por pasos personales o calles establecidas, por donde la gente habitualmente realiza sus recorridos; los bordes o límites que son reconocidos para sectorizar y categorizar qué está dentro o fiera del territorio como el barrio, la etapa o la cuadra, a la cual se pertenece; los nodos que son puntos de concentración como las plazas, las esquinas, confluencia de caminos; y los mojones constituidos por puntos de referencia que pueden estar lejanos al observador, como una montaña o un edificio.

Por su parte la geografía urbana puede hacer uso de los conceptos incluidos en el análisis de los mapas mentales, producto de la expresión de la percepción social, que por su puesto obedece a condiciones cotidianas, que a largo plazo constituyen su patrimonio, por ello para Palm "la geografia urbana debe centrarse en dos niveles diferentes para la búsqueda de una explicación: el estudio de las distribuciones espaciales y las interacciones ambientales en lugares y condiciones históticas especificas y el análisis de los procesos generales en los que estas distribuciones tienen lugar"s'.

De la mano con el protagonismo de la ciudad como objeto de estudio, la geografia urbana, brinda una temática fundamental al momento de

18 Lynch, Kevin. Administración del paisaje. Bogotá: Norma. 1992. 38p

1s Palm, R. Urban Geography: city structures, en Progress in Human Geography. Citado en: Universidad Libre a distancia. El desarrollo de la geografia urbana en la evolnción del pensamientó geográfico contemporáneo. Santos, Miguel. Revista Espacio, Tiempo y Forma. SerieVI-Geografia-, año 1992. [Online] [Versión PDF] [Citado 20 noviembre, 2008]. Disponible en: http/e-spacio.nned. es/fez 
dirigirse al patrimonio material, pues de acuerdo con Vinuesa y Vidal, ésta analiza "la evolución de la ciudad en el tiempo, hasta la imagen urbana actual"zo, esto ya no visto sólo como un "documento histórico" sino como una clave para identificar los patrones y características morfológicas que conviene conocer para idear alternativas de intervención que no vayan en detrimento de estructuras pasadas que en si mismas son patrimonio.

Estos mismos autores consideran que "temáticamente la nueva geografia se ocupa de la organización espacial de las sociedades, de los flujos espaciales de ideas, mercancías y personas, de las estructuras espaciales resultantes, etc. (...) tiene especial consideración con las relaciones ciudad-región, las redes urbanas, su origen y tipologías'21.

Con lo anterior, por un lado, cabe resaltar cómo las organizaciones espaciales están determinadas por acciones humanas que corresponden a las estructuras económicas, políticas, sociales y psicológicas de los individuos asentados en la ciudad, por lo tanto, deben ser, acogidos para idear planes urbanísticos coherentes a éstas, llevando al plano material los imaginarios colectivos concebidos al interior de los grupos e intereses ciudadanos. Por otro lado, mediante los aportes de la geografia urbana se puede concebir la relación de escalas espaciales que conlleven a análisis integrales, no sólo de dinámicas internas de la ciudad, sino como un todo conectado a regiones, y éstas con escalas mayores, estudiando realidades e identidades en su conjunto, cuya expresión tangible están en las particularidades de la morfología de la ciudad y los espacios patrimoniales.

Es de resaltar entonces, cómo la morfología de las ciudades estudiadas por la geografía urbana, está determinada por la presencia de un colectivo que la construye como resultado de la apropiación del espacio, convertido en territorio mediante sus prácticas sociales, que en el devenir del tiempo son legadas a otros individuos, desde los cuales también emerge el interés por mantener vivo ese patrimonio, pues hay un sentido de pertenencia al lugar tangible como bien lo argumenta. Vinuesa, al inferir que "sin entender la lógica de los

20 Vimesa, Julió, Vidal, Jesís. Los procesos de urbanización. Madrid: Sintesis. 1991. pp-11

${ }^{21}$ Ibid. 
procesos económico-sociales resulta imposible detectar las claves de la dinámica urbana, así como tampoco es posible explicar y valorar, en su justo témino, las realidades urbanas actuales. Comprender y valorar de forma adecuada la ciudad heredada resulta fundamental en el momento de formular propuestas de conservación o de transformación".

Actualmente, el legado patrimonial de los centros históricos, se encuentra en riesgo, por el deterioro urbano, entendido por Ignacio Gallo y María Martínez como la degradación de las condiciones sociales, económicas, naturales y espaciales, que pueden derivar de la terciarización de los usos y la demolición arquitectónica que genera la transformación morfológicay tipológica de las condiciones patrim oniales en aquella áreas ${ }^{22}$. Dichas condiciones provocan el desplazamiento de la población residente con lo que se debe considerar la pérdida del patrimonio "vivo" y la identidad directa de una comunidad con el lugar, junto con sus tradiciones e imaginarios, siendo este un motivo por el cual el espacio se convierte en "la tierra de nadie", lo que incentiva a establecer mecanismos de intervención, como las gestiones culturales integrales que incluyan diversos aspectos y la participación actores sociales, como lo son el sector público, las entidades privadas, la población residente y la transitoria, entre otros.

\section{La gestión cultural como una herramienta para el ordenamiento territorial}

Considerando el centro histórico como escenario para proyectar un tipo de desarrollo a escala de ciudad, ditigido por políticas sólidas de habitabilidad y funcionalidad, mejorando la calidad de vida de sus "consumidores", a la vez que se construyen estrategias de apropiación del lugar y el patrimonio local; se presenta entonces la necesidad de administrar y potenciar de una manera coherente los recursos con los que cllenta este espacio.

${ }^{22}$ Gallo, Ignacio. Martinez, Maria. La rehabilitación del barrio Las Cruces en Bogotá: una apuesta desde la academia. En: DELGADO, Maria Engenia; CARRIÓN, Fernando. et ál. E1 Centro Histórico objeto de estu dio e interven ción. Bogotá: Editorial Pontificia Universidad Javeriana, 2004.p 134. 
Para hablar más detalladamente de los matices en las gestiones culturales aplicadas a espacios patrimoniales, es necesario dirigirse a lo planteado por Femando Carrión, quien precisa que la apreciación espaciotemporal hacia las intervenciones en estos lugares tiene tres versiones: la tecnocrática, que expresa posiciones conservacionistas a ultranza mediante una jerga que antepone a los conceptos urbano-arquitectónicos el prefijo "re", teniendo asi, reconstrucción, rehabilitación, revitalización, rescate, restauración, recualificación, etc. La historicista que lo concibe como el testimonio, testigo o memorial del pasado inmutable, en donde las políticas se concentran en propuestas de peatonalización, en la realización de museos o en la reubicación del vendedor ambulante. Y por último, se encuentra la versión reminiscente que pone énfasis en el pasado bajo la versión nostálgica: "todo tiempo pasado fie mejor", con la cual se hace su valoración histótica, 1levando a comprenderlo como el lugar integrador del pasado con el futuro deseado ${ }^{23}$.

Ahora bien, en medio de esta variedad de líneas, es pertinente hacer un repaso de las diferentes tipos de intervención. Uno de ellos, es la restauración, la cual se enmarca en el conjunto de arquitectura monumental y que propicia los inventarios como bases de las políticas de renovación urbana y rehabilitación arquitectónica. Por su parte el mejoramiento y la renovación, ofrecen una fuerte connotación fisica, pues como expresa Rojas $^{24}$ ponen el acento en acciones sobre el entomo construido, y la rehabilitación, revitalización, regeneración y recuperación son términos que tienen una connotación económica y social de mayor peso, aunque sin descartar la dimensión fisica de las intervenciones.

Adicionalmente, "se entenderá por recuperación de áreas urbanas centrales el proceso a través del cual se promueve el mejor uso en términos sociales y económicos de una zona urbana central que padece deterioro social, económico y físico e infrautilización de sus activos, edificios, suelo, infraestructura o servicios públicos'ss.

En cuanto a la actividad turística, ésta ha tomado una visión cultural,

${ }^{29}$ Carrión, 2006. Op.cit.

${ }^{24}$ Rojas, Eduardo. Volver al Centro: la recuperación de las áreas urban as centrales.

Wash ington: Banco Interamericano de Desarrollo (BID). 2004. p.17

${ }^{25}$ Ibid. 
expresada en acoger los centros históricos como museos, centros culturales y calles peatonales, que requieren acciones hacia la solución de problemáticas especificas como el comercio ambulante e intereses como la "comunicación" entre el monumento y el espectador. Además al incorporar la vivienda dentro de las politicas de rehabilitación de los centros históricos (establecido en el Coloquio de Quito, 1977), se da prioridad a la conservación del uso residencial en estos lugares lo que promueve una dimensión social (calidad de vida, sentido comunitario, identidades), así como se valora la arquitectura popular.

Otro aspecto a tener en cuenta en la formulación de estrategias de gestión cultural, es el espacio público, donde convergen las identidades implícitas en los monumentos, las plazas y las edificaciones, con las actividades actuales de administración y legislación colectiva. En estas intervenciones se apunta hacia un centro histórico donde se superen las tensiones entre actores sociales, consolidando este espacio como un medio de comunicación que acoja las centralidades tanto urbanas como históricas, al servicio de la sociedad.

Con respecto a los entes más representativos para el disefio y ejecución de estrategias de gestión para los centros históricos, se halla en primer lugar el Estado, por medio de ótganos especializados como ministerios e institutos de cultura y patrimonio, en los que se deja implicito el sentimiento de arraigo territorial. A pesar de estas iniciativas públicas, se debe poner a disposición de la inversión privada estas labores, para aminorar el esfierzo de las economías locales; y por supuesto no se debe dejar de lado la participación de las organizaciones cindadanas que también deben comprometerse a la construcción y difusión de la conciencia urbana en tomo al patrimonio.

\section{Elementos a tener en cuenta para ordenar la "ciudad patrimonial"}

Para el tratamiento de sectores con valor patrimonial el desarrollo de politicas urbanísticas ha propiciado notables avances en cuanto a la conservación y mantenimiento de elementos físicos naturales y 
construidos, lo que determina funcionalidades socioeconómicas que pueden ser consideradas "motores" de desarrollo de la ciudad y de alcances nacionales e internacionales. Sin embargo, las estructuras y dinámicas del patrimonio en sí mismo albergan una complejidad mayor pues son producto de relaciones sociales, exigiendo de este modo, gestiones culturales integrales, logrando conectar el desarrollo físico y funcional con las características y valores inmateriales del patrimonio, como las historias identitarias colectivas, las perspectivas personales con las que construye territorialidad, imaginarios de espacios evocados, etc.

El patrimonio hallado en una ciudad, contiene un carácter píblico, ligado tanto al pasado como a la cotidianidad, por lo tanto promueve a los grupos sociales a hacer parte activa de la formulación y ejecución de alternativas de gestión, que no sólo respondan a sus problemáticas espaciales (falta de vías de comunicación, deterioro de mobiliario urbano, etc), sino al reconocimiento de su valoración simbólica de donde parten sus expresiones espaciales. Por lo tanto siguiendo a Palacio y Van der Hammen, "( ...) se debe defender la importancia de acercarse justamente a las representaciones y prácticas de los residentes (..) así como a las dinámicas sociales locales que dan sustento al capital cultural en los procesos de construcción de unas políticas públicas del patrimonio'rz6. En esta línea, se pueden nombrar los Planes de Ordenamiento Territorial, y los Planes Especiales de Protección del Patrimonio como algunas de las herramientas a usar en la consolidación de políticas comprometidas a difundir el patrimonio ya declarado, pero sobre todo a exaltar el patrimonio percibido o amenazado por el olvido, lo que implica análisis históricos, de percepción y urbanos, junto a las formulaciones de propuestas de diverso tipo (arquitectónica, urbanistica, social).

El planificar y ordenar la ciudad tomando en cuenta sus valores patrimoniales, impulsados mediante el quehacer geográfico y la gestión

${ }^{26}$ Universidad Externado de Colombia. Centro de Investigaciones sobre Dinámica Social. Facultad de Ciencias Sociales y Humanas. Palacio, Cristina, Van Der Hammen, Clara. Redes heterogéneas del patrimonió Los Casos del Centro histórico y el humedal Córdoba, Bogotá (Colombia). REDES- Revista hispana para el análisis de redes sociales. Vol. 13, Noº , Diciembre 2007. [Onilne]. [Version html]. [Citado 15 noviembre, 2008]. Disponible en: http/revistaredes.rediris.es 
cultural puede convertirse en una estructura metodológica de gran alcance, pues se incluyen dentro de las alternativas de intervención conceptos como la escala, la gobemabilidad, la sostenibilidad, y la participación ciudadana.

La concepción de escala, establece parámetros dentro la intervención, para que ésta mantenga un equilibrio y coherencia entre las unidades espaciales que conforman la zona patrimonial, y a su vez, debe darse de modo paralelo, con usos de suelo y actividades complementarias, incluso con las de la ciudad misma. En cuanto a la gobemabilidad, estará dirigida por politicas urbanísticas y referidas al patrimonio, a nivel de ciudad como el P.O.T y los planes especiales, además de la voluntad política comprometida con estos temas. Igualmente, es necesario construir escenarios de sostenibilidad de financiamiento, difusión e integración económica, que conviertan la revitalización del patrimonio en motor de desarrollo para la ciudad. Un íltimo elemento, y no menos importante, es la participación ciudadana, basada en fortalecer los lazos de identidad, mediante la concertación entre los diferentes actores, para la materialización de metas colectivas prolongando el alcance de las estrategias de gestión cultural.

Con el fin deidear propuestas de ordenamiento territorial para planear y estudiar la complejidad de la ciudad, se hace referencia a diferentes perspectivas geográficas, arquitectónicas, históricas, económicas, sociológicas, y urbanisticas, conjugadas en varias estrategias y acciones; las primeras establecen las líneas de acción que dirigen las decisiones a tomar en cada uno de los temas propuestos, y las segundas son el paquete de opciones precisas para el desarrollo de cada uno de los aspectos a intervenir en el espacio, haciendo más coherente y eficiente el proceso de gestión. 
Tabla No 1 . Estrategias y Acciones para ordenar la cindad-patrimon io

\begin{tabular}{|c|c|}
\hline ESTRATEGIAS & ACCIONES \\
\hline $\begin{array}{l}\text { Promover:"El paseo por } \\
\text { el centro histórico" }\end{array}$ & $\begin{array}{l}\text { Intervención a espacios abiertos: mantenimiento de Plazas, } \\
\text { reubicación de vendedores ambulantes, diseño plan vial } \\
\text { incluyendo algunas calles peatonales, estacionamientos } \\
\text { subterráneos, iluminación de calles y monumentos. } \\
\text { Ofrecer un recorrido seguro (presencia de vigilancia) y de } \\
\text { calidad cultural. }\end{array}$ \\
\hline $\begin{array}{l}\text { Mejorar la } \\
\text { habitabilidad }\end{array}$ & $\begin{array}{l}\text { Diseño de ofertas de vivienda para distintos niveles } \\
\text { socioeconómicos, en lotes subutilizados. } \\
\text { Asesorar y dar crédito a los habitantes cuyos predios se } \\
\text { encuentren deteriorados. }\end{array}$ \\
\hline $\begin{array}{l}\text { Equilibrar el uso } \\
\text { residencial y comercial }\end{array}$ & $\begin{array}{l}\text { Promover microempresas donde se emplee a la población } \\
\text { residente, invertir en su capacitación y brindar alternativas } \\
\text { de adecuación de predios para actividades comerciales } \\
\text { acorde con la zona (cafés, librerías, tiendas de artesanías, } \\
\text { etc) }\end{array}$ \\
\hline $\begin{array}{l}\text { Evaluar las } \\
\text { potencialidades y } \\
\text { restricciones del sector } \\
\text { patrimonial }\end{array}$ & $\begin{array}{l}\text { Realización de estudios que evalúen lafuncionalidad de los } \\
\text { equipamientos administrativos, culturales, asistenciales, } \\
\text { etc, al interior del sector patrimonial, para evaluar sus } \\
\text { potencialidades y restricciones de acuerdo con la demanda } \\
\text { de población residente y visitante. }\end{array}$ \\
\hline $\begin{array}{l}\text { Impulsar el desarrollo } \\
\text { de la oferta turística con } \\
\text { valores patrim oniales }\end{array}$ & $\begin{array}{l}\text { Crear una oficina de promoción de turismo en el sector. } \\
\text { Realizar actividades que integren la labor de museos, } \\
\text { iglesias, teatros, espacios públicos, entre otros. } \\
\text { Adecuación de inmuebles para uso turístico, cultural y } \\
\text { comercial (museos, restaurantes, cafés, almacenes de } \\
\text { artesanías, hoteles, hostales, etc). }\end{array}$ \\
\hline $\begin{array}{l}\text { Incentivar el } \\
\text { financiam iento de la } \\
\text { gestión cultural en el } \\
\text { sector histórico }\end{array}$ & $\begin{array}{l}\text { Creación de una Fundación de apoyo a las iniciativas de } \\
\text { gestión mediante auxilios, o contribuciones, por parte de } \\
\text { entidades públicas, privadas o mixtas, de carácter nacional } \\
\text { e internacional, que administre inmuebles, canalice sus } \\
\text { potencialidades, materialice políticas patrim oniales, etc. }\end{array}$ \\
\hline
\end{tabular}




\begin{tabular}{|l|l|}
\hline \multicolumn{1}{|c|}{ ESTRATEGIAS } & \multicolumn{1}{c|}{ ACCIONES } \\
\hline $\begin{array}{l}\text { Difundir del valor } \\
\text { patrimonial del sector } \\
\text { dentro de la educación básica y superior. } \\
\text { Impulsar la pedagogía patrimonial ciudadana, mediante } \\
\text { campañas, boletines informativos culturales, la. Intemet, } \\
\text { periódicos locales, radio y televisión, etc. Es decir, } \\
\text { formación de público para la cultura. }\end{array}$ \\
\hline $\begin{array}{l}\text { Reconocer los intereses } \\
\text { de los "consumidores } \\
\text { de la cultura" del } \\
\text { sector histórico }\end{array}$ & $\begin{array}{l}\text { Caracterizar la población visitante y residente del sector } \\
\text { histórico cultural mediante la obtención de una serie } \\
\text { de datos como los sitios que más le agrada y desagrada } \\
\text { del sector, frecuencia de visita, a qué le gustaría asistir, } \\
\text { condiciones de acceso al sector, entre otros. }\end{array}$ \\
\hline $\begin{array}{l}\text { Integrar los eventos } \\
\text { tradicion ales de la } \\
\text { población con la oferta } \\
\text { turística-cultural sector }\end{array}$ & $\begin{array}{l}\text { Rescatar e institucionalizar patrimonio intangible de } \\
\text { la población, al fortalecer festivales de artes plásticas, } \\
\text { escénicas, música, literatura, danzay audiovisuales. }\end{array}$ \\
\hline $\begin{array}{l}\text { Ciudady política } \\
\text { urbana: } \\
\text { Valorar del patrimonio } \\
\text { edificado }\end{array}$ & $\begin{array}{l}\text { Elaboración de planes parciales que integren altemativas de } \\
\text { del patrim on io edificado. Fortaleciendo las categorías e } \\
\text { instrumentos adm inistrativos de los bienes culturales. }\end{array}$ \\
\hline
\end{tabular}

Fuente: Elaboración propia

En este sentido, con la definición de líneas de trabajo ordenadas en estrategias y acciones dirigidas a un ordenamiento territorial donde tome protagonismo la conservación del patrimonio urbano, es necesario aplicar metodologías y fases técnicas como un estudio de normatividad vigente, inventarios de bienes patrimoniales, diagnósticos de la zona patrimonial, etc.

Estudio de normatividad vigente: Construcción de un soporte legal coherente con la realidad local, logrando más adelante, la formulación acertada de las políticas que dirigirán los programas de gestión cultural.

Espacialización de problemáticas: uso de Sistemas de Información Geográfica (SIG), para definir las "Zonas de actuación prioritaria", de acuerdo a procesos de planeación y desarrollo urbano. 
Estudio de técnicas para la restauración y la rehabilitación: evaluación de las técnicas constructivas y materiales, más pertinentes al conjunto edificatorio presente en el sector histórico.

Estudio de gestión institucionat: análisis de la capacidad y las opciones de financiamiento, cohesión social, y organizacional de los actores que dirigen la propuestas de gestión del patrimonio ${ }^{27}$.

\section{A manera de conclusión}

El estudio de la ciudad y la posibilidad de relacionar el patrimonio con los procesos de planificación y ordenamiento territorial en las distintas escalas espaciales (conjuntos históricos, barrios, ciudades, regiones, etc), permite la formulación de propuestas dirigidas hacia la valoración y revitalización del mismo, que conlleve a las sociedades no sólo a fortalecer su identidad presente, sino su vínculo con el pasado, además de garantizar la permanencia en la memoria colectiva del significado de los espacios, convertidos en lugares, que brinden un lazo de continuidad con las generaciones venideras.

Como se mencionó en un apartado de este escrito, las corrientes geográficas involucradas en esta ocasión con el estudio del patrimonio, como herramienta en el ordenamiento territorial de la ciudad, son tan "sólo por mencionar algunas", pues de acuerdo al objetivo perseguido, la geografia propone un abanico de enfoques, con aportes conceptuales y metodológicos, que bien pueden constituirse en el soporte de estudios interdisciplinares que integren muchos de los elementos, actores y dinámicas que convergen en la ciudad.

Considerando el patrimonio de una sociedad en el espacio de la ciudad, como uno de los "ejes" en la formulación de propuestas para la planificación y el ordenamiento del territorio, se puede pensar en su alcance para la definición de modelos territoriales deseados, incluidos en

${ }^{27}$ Si se quiere saber del estado de avance en que se encuentran cada una de estas técnicas en la gestión cultural y el ordenamiento territorial de los barrios La Merced y San Antonio de la cindad de Cali, ver Capitulo 3 - Propuesta de gestión cultural (Altennativas de revitalización), en: Gestión Cultural y Uso Social del Centro Histórico. Barrios La Merced y San Anton ió de la cindad de Cali. Tesis Universidad del Valle. Facultad de Human idades. 2008. 
Planes de Ordenamiento Territorial y Planes de Desarrollo, partiendo de la identificación de los recursos hallados en los ámbitos espaciales más próximos, contribuyendo de este modo a exaltar el patrimonio declarado y a establecer ese patrimonio vivido en otros lugares de la cindad alejados del centro histórico, reconociendo que el sentido de la ciudad-patrimonio, se encuentra en permanente construcción. 


\section{Bibliografía}

Abler, Ronald; Adams, John S., y Gould, Peter: Spatial organization. The Geographer's view of the World, Londres y Englewoods Cliffs, Prentice Hall International Inc., 1972, p- 354. Citado en: Defuición de lo urbano. CAPEL, Horacio. Revista Geocritica, publicaciones sobre geografia y ciencias sociales. $\mathrm{N}^{\mathrm{N}} 138$. VOnline]. [Versión PDF]. [Citado 28 julio, 2007]. Disponible en: www.ub.geocrit/sv-33 htm

Ballart, Josep. El patrimon io histórico y arqueológico: valor y 1180. Barcelona: Arie1, 1997.

Buraglia, Pedro; Pérgolis, Juan; Moreno, Danilo. et ál, E1 Barrio, fragmento de ciudad Bogotá: Barrio Taller. 1998.

Buttimer, A. Hogar, campo de movimiento y gentido del lugar. 1985. En: Garcia, Ramón. Teoria y método en la geografia humana anglosajona. Ariel, Barcelona, 1978.

Carrión, Fernando. Centro Histórico: relación social, globalización y mitos. En: Desarrollo cultural y gestión en centros históricos. Quito: FLACSO, 2000.

Documento final del Coloquio de Quito, Proyecto Regional de Patrimonio Cultural, PNUD/ UNESCO, Quito, 1977, citado por Hardoy, Jorge Enrique y Gutman, Margarita. Impacto de la urbanización de los centros históricos de Iberoamérica. Tendencias y perspectivas. Madrid: MAPFRE, 1992.

Gallo, Ignacio. Martinez, Maria. La rehabilitación del barrio Las Cruces en Bogotá: una apuesta desde la academia. En: Delgado, Maria Eugenia; Carrión, Fernando. et ál. El Centro Histórico objeto de estudio e intervención. Bogotá: Editorial Pontificia Universidad Javeriana, 2004.

Lynch, Kevin. Administración del paisaje. Bogotá: Norma.1992. 38p

Ministerio de Cultura. Ley 397, 1997 [online]. Versión HTML. Santafe de Bogotá 1997. [Citado 26 de octubre, 2006]. Disponible en: www.mincultura.gov.co/legislación

Palm, R. Urban Geography: city structures, en Progress in Human Geography. Citado en: Un iversidad Libre a distancia. El desarrollo de la geografia urbana en la evolución del pensamiento geográfico contemporáneo. Santos, Miguel. Revista Espacio, Tiempo y Forma. SerieVI- Geografia-, año1992. [On line] [Versión PDF] [Citado 20 noviembre, 2008]. Disponible en: http/e-spacio.uned.es/fez

Rojas, Eduardo. Volver al Centro: la recuperación de las áreas urbanas centrales. Wash ington: Banco Interamericano de Desarrollo (BTD). 2004.

Samer, Carl. Introducción a la geografia histórica. Revista Polis. [Online]. [Versión htm1]. [Citado 18 de noviembre, 2008]. Disponible en: www.revistapolis.cl/8/geo.htm

Silva, Armando. Imaginarios urbanos. Bogotá y Sao Paulo: cultura y comunicación urbana en América Latina. Bogotá: Tercer Mundo, 1992.

Universidad Complutense. Centro histórico, intervención urbanistica y análisis urbano. Vinuesa, Miguel. Revista Anales de Geografia. No 11. Año 1992. [Onine]. [Yersión PDF]. [Citado 24 noviembre, 2008]. Disponible en: http/dialnet.un irioja es/gervlet/revista

Universidad Externado de Colombia. Centro de Investigaciones sobre Dinámica Social. Facultad de Ciencias Sociales y Humanas. Palacio, Cristina; Van Der Hammen, Clara. Redes heterogéneas del patrimonió Los Casos del Centro histórico y el humedal Córdoba, Bogotá (Colombia). REDES-Revista hispana para el análisis de redes sociales. Vol.13, $\mathrm{N}^{\circ} 1$, Diciembre 2007. [Onilne]. [Version himl]. [Citado 15 noviembre, 2008]. Disponible en: http//revista-redes.rediris.es 
Universidad de Murcia. Millán, Mercedes. La geografia de la percepción : una metodología de análisis para el desarrollo rural. [Online]. [Versión PDF]. Revista Papeles de Geografia. Murcia, España.14 de febrero, 2005. [Citado 23 de septiembre, 2007]. Disponible en: www. um.es/dp-geografia/

Universidad delNorte. Grupo de Investigación en Arqueologia, Historia y Estudios Urbanos del Caribe Colombiano del Departamento de Historia y Ciencias Sociales. Transformaciones de la imagen de un a cindad: repercusiones de la renovación urbana. Vergara, Ricardo. Memorias: Revista digital de Historia y Arqueologia desde el Caribe. [Online]. [Versión PDF]. Barranquilla. Septiembre 15 de 2006. [Citado 7 de septiembre, 2007]. Disponible en www.un inorte edu.co/publicaciones/memorias

Vinuesa, Julio; Vidal, Jesús. Los procesos de urbanización. Madrid: Sintesis. 1991. pp-11.

Recibido: febrero 2008

aceptado: agosto 20 de 2008 